The Canadian Journal of Higher Education, Vol. XXIV-2, 1994

La revue canadienne d'enseignement supérieur, Vol. XXIV-2, 1994

\title{
Predictors of Time to Completion of Graduate Degrees
}

\author{
PETER M. SHERIDAN* \& SANDRA W. PYKE*
}

\begin{abstract}
A multiple regression procedure was utilized to predict the time taken to complete graduate degree requirements for 395 master's and 79 doctoral students at a large Canadian university. Selected demographic (e.g., sex, age, marital status, registration status, citizenship), academic (e.g., undergraduate and graduate GPA, discipline, type of program) and financial support variables (funding received from internal and external scholarships and from research, graduate and teaching assistantships) were used as independent variables. Results for master's students indicate that full-time registration, increased financial support, higher graduate GPA and enrolment in a humanities discipline significantly decrease time to completion. Conversely, a thesis requirement and Canadian citizenship are associated with significantly slower degree progress. For doctoral students, enrolment in a natural sciences discipline, Canadian citizenship, full-time registration and increased funding significantly decrease the time taken to complete the doctorate.
\end{abstract}

\section{Résumé}

Afin de prédire le temps requis pour satisfaire aux exigences des études supérieures, nous avons utilisé une méthode de régression multiple pour évaluer 395 étudiant(e)s de maîtrise ainsi que 79 étudiant(e)s de doctorat d'une grande université canadienne. Les critères démographiques suivants (le sexe, l'âge, le statut social, le type d'inscription et la citoyenneté), ainsi que le genre d'aide financière que les étudiant(e)s reçoivent (bourses internes et externes,

* York University 
bourses de recherche, charges de recherche ou d'enseignement) ont été utilisés comme variables indépendantes. En ce qui concerne les étudiant(e)s de maîtrise, les résultats démontrent qu'une inscription à plein temps, une aide financière accrue, un GPA plus élevé et l'étude des sciences humaines réduisent considérablement le temps requis pour compléter la maîtrise. Inversement, les exigences d'une thèse et la citoyenneté canadienne sont associées à des progrès beaucoup plus lents. En ce qui concerne les étudiant(e)s de doctorat, l'étude des sciences humaines, la citoyenneté canadienne, une inscription à plein temps ainsi qu'une aide financière élevée réduisent le temps requis pour compléter le doctorat.

\section{Introduction}

Unlike the study of graduate student attrition (Pyke \& Sheridan, 1993), the length of time taken to complete graduate degrees has been the focus of considerable attention for several decades (Abedi \& Benkin, 1987; Baird, 1990; Berelson, 1960; Bowen \& Rudenstine, 1992; Carmichael, 1961; Filteau, 1992; Harmon, 1978). Despite widespread interest in the topic and publication and interpretation of some large scale data sets (National Research Council, 1989), the desirability of more systematic data collection and dissemination with respect to graduate student progress within individual institutions has been recognized (Cude, 1991; Yeates, 1991). Additionally, there is a need for more elaborate forms of statistical analysis to enable assessments of the differential contribution of various key factors affecting the time taken to complete graduate programs. Furthermore, most of the literature on the completion time variable confounds master's and doctoral level training. The common statistic used is the total time to the doctorate (TTD) which refers to the time between receipt of the baccalaureate and receipt of the doctorate, including any time spent out of university after obtaining the undergraduate degree and prior to entry into graduate school. Finally, more information on the situation in Canadian doctoral programs would be useful. The present study is designed to address these issues.

Reports on the average or median time taken to complete graduate degrees vary as a function of the year the data were collected. In general, earlier studies report shorter completion times. For example, based on the National Research Council survey (1989), Evangelauf (1989) comments that "the typical new doctoral recipient spent a median 6.9 years in graduate school, up from 6.1 years in 1977. Over the same period, the total median time that elapsed between the earning of a bachelor's degree and a doctorate rose to 10.4 years from 8.7 years" (p. A13). However, the magnitude of the increase may be artifactually 
expanded as a consequence of grouping students by year of graduation rather than year of entry into graduate school (Bowen \& Rudenstine, 1992).

As noted above, the operational definition of the dependent variable will obviously affect the time to completion statistic; largest values result from use of the TTD index. Using the registered time to the doctorate (RTD), which excludes time prior to entry into graduate school as well as time not enrolled at the university (e.g., time spent on leave), Tuckman, Coyle, and Bae (1989) report an average RTD of 5.63 years in 1967 as compared with 7.02 years in 1986. Comparable figures for the average TTD are 8.19 years and 9.84 years respectively. A more precise measure of time to completion (time elapsed from admission into a doctoral program and graduation) was utilized in a study of the 1980 cohort of doctoral students admitted to doctoral programs in Ontario universities (Yeates, 1991). The median time to completion was five years.

Among the most consistent findings in the literature is the relationship between field of study and time to completion. Duggan (1989) reported that the average length of time taken to complete doctoral degrees at the University of California at Berkeley between 1980 and 1987 was 6.9 years; however, considerable variability across disciplines was observed. Students in languages and literary studies, in the arts, and in the social sciences took over eight years on average to complete their degrees $(8.9,8.6$ and 8.4 years respectively), while students in engineering and in the physical and biological sciences took six years or less on average to complete their program requirements (5.5 years, 6.0 years and 6.2 years respectively). These findings are more or less typical. Yeates (1991) for example, reports that the fastest time to completion (approximately 4.5 years) occurred with science students. Students in professional programs occupied an intermediate position while students in social science and humanities disciplines achieved a median completion time of 5.6 years. Fletcher and Stren (1992) conducted a survey of recent graduates of the University of Toronto and similarly reported that students in the humanities, social sciences, education and law take significantly longer on average to complete their doctoral programs than do students in the physical, biological and life sciences and engineering.

Another variable explored by several investigators is the relationship between the financial support package available to the student and the time taken to complete the degree. In a study of over 4000 doctoral degree recipients at the University of California at Los Angeles, Abedi and Benkin (1987) found that students relying on their own earnings as their primary source of income required, on average, two years longer to complete their doctoral training than 
those students whose income derived from other sources. With respect to the latter, students awarded grants and fellowships took longer to complete their doctorates than did those supported through research or teaching assistantships. These authors speculate that the net effect of funding via grants and fellowships is an increased amount of time spent pursuing non-degree-related activities. Nonconvergent results were reported by Tuckman, Coyle and Bae (1990), who found that fellowship funding contributed to shorter completion times, while personal financing, research or teaching assistantships increased TTD. Bowen and Rudenstine (1992) also observe that students forced to rely on their own financial resources have longer times to completion than students who receive financial aid and note further that the source or form of funding is much less relevant. However, their findings vis-à-vis fellowships versus teaching assistantships are consistent with those of Tuckman et al. (1990). Fletcher and Stren (1992) conclude that the "impediments to a speedy completion of the Ph.D. at the University of Toronto are primarily financial" (p. 38) and are concentrated in humanities and social science disciplines, thus accounting for the longer time to completion in these fields.

Gender differences in time to completion is another popular variable of study. Most investigators discovering such differences find that female students take longer to complete their degree requirements than do males (Tuckman et al., 1990), although some researchers report that gender differences only appear in certain fields or the position of each sex may be reversed, depending on the discipline in question (Bowen \& Rudenstine, 1992; MacMillan, 1989). It has been suggested that gender differences reflect the concentration of the sexes in certain disciplines (i.e., that women are concentrated in disciplines with long completion times, such as the humanities) or that they reflect gender-based differences in levels and type of financial support, or various other factors (Berg \& Ferber, 1983). However, Sheinin (1989) notes that, with the exception of the life sciences and education, completion times for doctoral degrees at the University of Toronto are almost universally longer for women than for men (6.1 years for women and 5.6 years for men). Yeates (1991) also reports that male students in the 1980 doctoral cohort in Ontario had a faster median time to completion than female students (4.7 years versus 5.3 years). However, many studies (e.g., those of Sheinin and Yeates) fail to subject these results to statistical analysis; and, hence, it is difficult to determine whether differences of the magnitude observed are significant.

Various other variables examined in terms of their relationship to TTD include citizenship, marital status, number of dependents, age, unemployment 
rates, number of full-time faculty and level of federal research and development support received by the university. With respect to the citizenship factor, Yeates (1991) reports that foreign students completed their doctoral degrees more quickly; the median time to completion for foreign students was four years as compared with five years for domestic students. Decreased time to the doctorate was found to be associated with married status and having dependents while longer TTD was found in conjunction with being older at entry to graduate school, more full-time faculty, more research and development support and higher unemployment rates (Tuckman et al., 1990).

There are relatively few available studies dealing with the length of time to degree completion at the master's level. McLennan (cited in Marr \& McPherson, 1992) reported an average length of 35 months to the master's degree in a large cohort of graduate students at the University of Saskatchewan. He found differences in length of time to degree by area of study, with students in the humanities and fine arts requiring 41 months on average, followed by students in the physical and engineering sciences ( 36 months), students in the social sciences ( 35 months) and students in the life sciences ( 33 months). McLennan found no effect of undergraduate grades, gender of student, or scholarship awards on length of time to degree completion. He did find that Canadian students required longer to complete their master's degrees than did foreign students and that the thesis option required more time in the life and social sciences than did the coursework-only option.

Marr and McPherson (1992) provided descriptive information for 1985 and 1987 on 29 master's programs in five Ontario universities which do not offer doctoral training. These authors found a median time to completion of seven terms ( 28 months), with a range of six to ten terms ( 24 to 40 months). Longer times to degree completion were observed in the physical and biological sciences. Longer mean times to completion were also reported for programs with thesis requirements as opposed to major research projects in combination with coursework or coursework alone.

Sheinin (1989) notes that the average time to completion of master's degrees at the University of Toronto was 2.1 years with women completing slightly more quickly ( 2.0 years) than men ( 2.4 years). As has been reported with respect to completion time in doctoral programs, some area of study differences were observed, with longer times to completion in education (2.9 years) and the life sciences (2.4 years) and shorter times in the humanities (1.8 years) and social science ( 1.9 years) disciplines.

This brief review of the current literature on length of time to graduate degree completion reveals a number of important limitations. Most 
investigations have focused on doctoral candidates, while much less attention has been paid to length of time taken to complete master's degrees (Marr \& McPherson, 1992; Sheinin, 1989; Sheridan, 1992). A number of studies provide descriptive and qualitative information regarding the scope of the problem, but do not provide information on associated or causal factors of increased time to the degree. Many authors fail to take into account such potentially significant variables as gender of student and availability and distribution of financial support. Nor do most researchers attempt to determine the relative importance of the various relevant variables. The present investigation was designed to identify the differential contribution of a number of demographic, academic and financial factors on the time taken to complete master's as well as doctoral degrees.

\section{Method}

\section{Subjects}

From a simple random selection procedure, a group of 698 graduate students admitted to various disciplines at York University, between January 1, 1975 and December 31, 1985, was identified. A total of 474 of these students successfully completed all program requirements (395 master's and 79 doctoral students) and this subset constitutes the sample for the study. The small number of graduated doctoral students selected via this procedure reflects the smaller number of doctoral admissions, the higher dropout rate for doctoral students and the fact that some Ph.D. students fail to complete within a ten year time frame. As all disciplines have either one- or two-year master's (M.A. and M.Sc.) degree programs, the selection of this ten-year cohort permitted assessment of length of time to degree completion across a series of master's classes. In addition, it was expected that the ten-year period of the investigation would allow sufficient time for almost all doctoral (Ph.D.) candidates beginning in January, 1975 to have either withdrawn or to have convocated by December, 1985.

Students from graduate programs in three discipline areas, natural sciences, social sciences and humanities, were included in this investigation. Natural science disciplines consisted of biology, chemistry, mathematics, and physics; social science disciplines encompassed economics, exercise and sports science, geography, political science, psychology, social and political thought, social anthropology, and sociology; and humanities disciplines included art history, English, history, and philosophy. 


\section{Variables}

The selection of variables was determined primarily by the level of support they had received in the literature (Sheridan, 1990). A secondary consideration was that the variables be available in relatively standardized form to ensure reliable retrieval from the archival record system. Twenty variables were selected for investigation as follows.

Demographic variables. These included the gender of the student, the registration status (full- or part-time) and marital status of the student at the point of entrance into the graduate program, the student's age, the square of the student's age, and citizenship status. Since graduate students frequently move from full- to part-time status once residency requirements are met, determination of status was based on the student's initial registration as either a full- or part-time student. The age-squared variable was selected on the basis of a rationale which would allow for the possibility that the relationship between age and degree progress might be nonlinear in the sense that both younger and older students might have longer completion times than those in a middle age range. The quadratic term was therefore made available to the regression equation in case an adequate accounting for age should require it. Citizenship status comprised three levels: Canadian, landed immigrant, or foreign citizen.

Academic variables.

These included the undergraduate and graduate grade point averages (GPAs) of the student, the student's discipline area, the type of program chosen, and whether the student had ever taken a leave of absence (LOA).

Undergraduate GPA was calculated as the average of the student's grades in the final two years of undergraduate study; the graduate GPA of the student was calculated as the weighted (half- or full-course equivalents) average of the student's grades in the master's or doctoral years.

The student's discipline area was classified as natural sciences, social sciences, or humanities. The type of program variable was applicable to master's students only because the type of program for students at the doctoral level is uniform across discipline areas (i.e., coursework plus a dissertation). Type of program for master's students was dichotomously coded for the regression analyses as either coursework plus thesis or coursework alone or with a major research paper. Finally, whether the student had ever taken a LOA during the time spent in the master's or doctoral program was coded simply as "yes" or "no".

Financial variables. These included type and amount of funding from nine different sources as well as the average-amount of funding from all 
sources. Funding sources considered were internal scholarships, research, graduate and teaching assistantships (RAs, GAs and TAs), Ontario Graduate Scholarships (OGS), fellowships granted by the Social Sciences and Humanities Research Council (SSHRC), the National Science and Engineering Research Council (NSERC) or the Medical Research Council (MRC), as well as a miscellaneous category including various other grants and scholarships.

To accommodate variability in program regulations relevant to student support (e.g., TAs are not permitted for master's students in some disciplines), to minimize variation in levels of support across programs and years, and to avoid a time confound, the predictor employed was an averaged amount of funding from each source over the student's participation in the graduate program. Monetary values (considered across students by year) were transformed into $z$-scores. The standardized scores were then averaged across an individual student's "history" in the graduate degree program to produce a "profile" of that student's earnings in each of the financial categories.

Interaction terms. As recommended by Hosmer and Lemeshow (1989), interaction terms used were chosen on the basis of interpretability, logic, and support received in the literature. Five interaction terms were computed: gender by marital status, gender by registration status, registration status by marital status, gender by type of program, and registration status by type of program. The latter two interactions were not utilized in the regression analyses for doctoral students since all doctoral candidates are required to complete a dissertation.

Dependent variable. Separate multiple regression analyses (SPSS, 1988) were carried out for master's and doctoral students. In both cases, the dependent variable was the student's length of time in the program, computed as the time elapsed between date of entry into the graduate program and date of conferral of the master's or doctoral degree.

In both analyses, the regression equation was built with forward, stepwise entry. It should be noted, however, that identical results were obtained with backward regression. Stepwise regression provides a useful and effective means of studying outcomes which have received little prior attention or are unknown (Draper \& Smith, 1981). P-in was set at 0.05 and p-out at 0.10 in order to identify as many possible predictors of length of time to degree completion as possible.

Following Hosmer and Lemeshow (1989), the procedure utilized for selection of significant independent variables and interactions involved: (1) stepwise selection of main effects; (2) forced entry of the main effects significant on step (1); (3) stepwise selection of interaction terms given the main effects variables in the model. 


\section{Results}

\section{Sample Characteristics}

Descriptive data for the sample of 395 master's and 79 doctoral students, disaggregated by level of study and selected demographic and academic independent variables, are presented in Table 1. Univariate statistical analyses are not reported here, given the results of the more elaborate multiple regression solutions, but may be found in Sheridan (1990).

\section{Regression Analysis - Master's Students}

The results of the regression solution for master's students are presented in Table 2.

Only seven of the 20 possible independent variables were significantly related to a graduated student's length of time in a master's program. Of the demographic variables, two are significant predictors of length of time to degree completion. Registration status is the single most important independent variable, accounting for approximately $16 \%$ of the variance in length of time to degree completion. Full-time status decreases length of time to degree completion. The second significant demographic variable, citizenship, reveals that Canadian citizenship is associated with longer times to degree completion.

Four of the academic variables (type of program, ever having taken a LOA, graduate GPA and discipline area) were significant predictors of length of time to degree completion. Enrolment in a program with a thesis requirement accounts for approximately $11 \%$ of the variance in the dependent variable and is the second most significant variable overall. A thesis requirement dramatically increases the length of time spent in the master's program relative to programs requiring coursework only or coursework plus a major research paper. As expected, taking a leave of absence at some point during the master's years increases the length of time spent in the program and accounts for roughly $6 \%$ of the variance. Participation in a humanities discipline decreases length of time required to complete the master's degree. Finally, higher graduate GPAs are found in conjunction with faster completion times.

Only one of the financial variables was found to be a significant predictor of length of time to degree completion at the master's level. As the average amount of funding from all sources (i.e., assistantships, scholarships and fellowships) increases, time spent in the program decreases. Of the interaction terms, only registration status by type of program was made available to the regression analysis (since both were significant main effects), and it was not significant. In 
Table 1

Length of time to degree completion for graduated students by level and selected demographic and academic independent variables

Master's

Doctoral

\begin{tabular}{|c|c|c|c|c|}
\hline $\mathrm{N}$ & Mean & $\begin{array}{c}\text { COMPARISON } \\
\text { VARIABLE }\end{array}$ & $\mathrm{N}$ & Mean \\
\hline \multicolumn{5}{|c|}{ GENDER } \\
\hline 242 & 2.34 & Male & 48 & 5.22 \\
\hline 153 & 2.36 & Female & 31 & 5.92 \\
\hline \multicolumn{5}{|c|}{ REGISTRATION STATUS } \\
\hline 317 & 2.10 & $\mathrm{~F} / \mathrm{T}$ & 74 & 5.51 \\
\hline 78 & 3.37 & $\mathrm{P} / \mathrm{T}$ & 5 & 5.25 \\
\hline \multicolumn{5}{|c|}{ CITIZENSHIP } \\
\hline 284 & 2.45 & Canadian & 52 & 5.26 \\
\hline 49 & 2.44 & Landed Immigrant & 12 & 6.12 \\
\hline 62 & 1.82 & Foreign & 15 & 5.80 \\
\hline \multicolumn{5}{|c|}{ DISCIPLINE AREA } \\
\hline 83 & 2.54 & Natural Science & 15 & 3.53 \\
\hline 188 & 2.39 & Social Science & 48 & 5.97 \\
\hline 124 & 2.16 & Humanities & 16 & 5.89 \\
\hline \multicolumn{5}{|c|}{ PROGRAM TYPE } \\
\hline 183 & 2.01 & Course & - & - \\
\hline 114 & 2.45 & MRP & - & - \\
\hline 98 & 2.86 & Thesis & 79 & - \\
\hline 395 & 2.35 & TOTAL & 79 & 5.49 \\
\hline
\end{tabular}


Table 2

Multiple linear regression of length of time to master's degree completion

\begin{tabular}{lcccc} 
Variable & Beta In & Sig F & $\mathrm{R}^{2^{*}}$ & $\mathrm{R}^{2} \mathrm{Ch}$ \\
\hline Registration status & -.4010 & .000 & .1608 & .1608 \\
Thesis required & .3349 & .000 & .2680 & .1071 \\
Ever taken LOA & .2446 & .000 & .3274 & .0594 \\
Average funds & -.1997 & .000 & .3526 & .0252 \\
Graduate GPA & -.1067 & .000 & .3634 & .0108 \\
Humanities & -.0912 & .000 & .3707 & .0073 \\
$\begin{array}{l}\text { Domestic citizen } \\
\text { * Note: } \mathrm{R}^{2} \text { reflects the proportion of the original variance in the dependent variable }\end{array}$ \\
$\begin{array}{l}\text { accounted for by the regression equation with variables up to and including the row } \\
\text { under examination. }\end{array}$ \\
\hline
\end{tabular}

total, the seven independent variables combined account for approximately $38 \%$ of the variance in length of time to degree completion at the master's level.

\section{Regression Analysis - Doctoral Students}

The results obtained from the regression analysis for doctoral students must be interpreted with some degree of caution because of the relatively small sample size (79) to predictor (19) ratio. Table 3 displays the results of the analysis.

Only five of the 19 variables available to the regression solution were statistically significant. Registration status and citizenship are again the only significant demographic variables, accounting for $6.4 \%$ and $4.4 \%$ respectively of the variance in length of time taken to complete doctoral programs. Full-time and Canadian students require less time overall to complete doctoral requirements as compared with part-time students and landed immigrant and foreign students. The only significant academic variable, accounting for $26 \%$ of the variance, is discipline, with students in natural science disciplines exhibiting the fastest completion times. Two of the financial variables added significantly to the regression solution. The average amount of funding received from all sources accounted for $3.8 \%$ of the variance and the average amount of funding from graduate assistantships accounted for $6.5 \%$ of the variance. In both cases, 
Table 3

Multiple linear regression of length of time to doctoral degree completion

\begin{tabular}{|c|c|c|c|c|}
\hline Variable & Beta In & Sig F & $\mathrm{R}^{2^{*}}$ & $\mathrm{R}^{2} \mathrm{Ch}$ \\
\hline Natural Science & -.5122 & .000 & .2623 & .2623 \\
\hline Grad assistantships & -.2635 & .000 & .3277 & .0653 \\
\hline Domestic citizen & -.2101 & .000 & .3716 & .0440 \\
\hline Average funds & -.2098 & .000 & .4100 & .0384 \\
\hline Registration status & -.2772 & .000 & .4739 & .0639 \\
\hline
\end{tabular}

as the amount of funding increases, the length of time in the doctoral program decreases.

None of the interaction terms was made available to the regression analysis because the prior main effects were not significant. The five significant variables accounted for slightly more than $47 \%$ of the variance in length of time to degree completion at the doctoral level.

\section{Discussion}

\section{Degree Progress at the Master's Level}

The present investigation is one of the few studies to focus attention on the length of time required to complete master's degrees (Marr \& McPherson, 1992; Sheridan, 1992). Although some of the results parallel those obtained from the research on doctoral degree progress, other findings were unique and merit further consideration.

The regression solution for master's students supports the findings of other researchers (Girves \& Wemmerus, 1988; Ott, Markewich, \& Ochsner, 1984) that registration status is an extremely important variable in degree progress at this level. In the present investigation, registration status accounts for the largest proportion of the variance in, and is the single most important predictor of, length of time to completion at the master's level. Being a full-time student significantly decreased length of time to degree completion. Part-time graduate 
students may be doubly disadvantaged since they face not only the difficulties of part-time study, but also appear to be of significantly lower academic standing at the point of admission than those registering as full-time candidates (Sheridan, 1990).

Assuming that grades reflect ability, higher-ability students complete their degrees faster than those of lower ability, although only about one per cent of the variance in the dependent variable is accounted for by graduate GPA. Undergraduate GPA was not a significant predictor of length of time to degree completion at the master's level. Given that undergraduate GPA is an important selector criterion for graduate study, this lack of relationship with the length of time to complete the degree suggests the need for further stúdy of the relevance of undergraduate GPA to graduate work.

Students required to complete a thesis as part of their program take significantly longer to complete their master's degrees than those doing coursework only or coursework plus a major research paper, a finding in keeping with other studies (McLennan, cited in Marr \& McPherson, 1992; Marr \& McPherson, 1992). This is in spite of the fact that students undertaking the thesis option were significantly more likely than those in one of the other two types of programs to be of higher academic standing at the point of admission to the graduate program (Sheridan, 1990). This indicates that, higher GPA notwithstanding, completing a thesis project significantly delays one's progress in a master's program.

Ever having taken a LOA was also a predictor of length of time to degree completion at this level. Students who had ever taken a LOA required significantly longer to complete their degrees than those who had not. It should be noted that this finding is not necessarily intuitive; theoretically, although on an official LOA, students may continue to do some work on their thesis, and/or to complete outstanding course assignments - which might expedite their progress or at least not hinder it. This does not appear to be the case, however.

The average amount of funding received from all sources was the only financial variable significant in the regression solution for length of time to degree completion at the master's level. The finding that increased funding decreases length of time to degree completion supports the conclusion of many researchers (Abedi \& Benkin, 1987; Bowen \& Rudenstine, 1992; Fletcher \& Stren, 1992; Tuckman et al., 1989, 1990), that personally financing one's own education at the graduate level significantly increases time to degree completion. At the master's level, it does not appear that the source of financial support (e.g., assistantships vs. scholarships) affects length of time to completion, as is 
thought to be the case at the doctoral level (Abedi \& Benkin, 1987; Bowen \& Rudenstine, 1992; Tuckman et al., 1990). This finding may reflect the relative rarity of large grants and fellowships (e.g., NSERC, SSHRC, MRC) at the master's level, and therefore indicates the greater importance of funding received from university sources (e.g., internal scholarships, RAs, GAs, TAs).

Being in a humanities discipline significantly decreased length of time to master's degree completion. This finding is notably independent of the influence of the type of program chosen by the student, which is itself significant in the regression solution. Expectations and program requirements for master's level candidates may be more precisely delineated in these disciplines, which, in combination with close supervision and monitoring, could yield faster completion times. In any event, further research is required to illuminate this result.

Finally, citizenship of the student was significantly related to length of time to degree completion at the master's level. These results support the observations of others that foreign students at both the master's and doctoral level complete degrees faster than domestic students (McLennan, cited in Marr \& McPherson, 1992; Ott et al., 1984; Yeates, 1992). This may reflect the fact that foreign students are usually unable to work or to remain in the country if they withdraw from school, or the fact that such students are often under intense pressure to complete their degrees and return home to work.

Contrary to a number of other reports, gender of student was not a significant predictor of length of time to degree completion. Age and marital status were also not significant predictors of length of time to the master's or doctoral degree. Although these results replicate the findings of some other investigators (e.g., McLennan, cited in Marr \& McPherson, 1992; Ott et al., 1984), they do not support the results reported by Tuckman et al. (1990) for doctoral degree completion.

\section{Degree Progress at the Doctoral Level}

Multiple linear regression, like all statistical procedures, is sensitive to sample size. The minimum suggested requirement for stepwise regression-four cases per independent variable-is far less than the ideal case-to-variable ratio of forty to one (Tabachnick \& Fidell, 1983). The number of doctoral graduands in the present study (79) meets the minimum suggested case-to-variable ratio, but limits the generalizability of the information. An additional limitation is imposed in that the data derive from only one institution. Although the results obtained in this study appear to be more or less consistent with the findings reported by other researchers, the results of the multiple regression solution for doctoral students should be treated as preliminary, suggestive of possible 
variables for inclusion in future studies employing larger samples selected from several contributing universities across the country. Such future research could reveal important national trends as well as regional differences.

As was the case at the master's level, registration status is a highly significant predictor of length of time to completion of the doctorate. Being a full-time student significantly speeds progress through the doctoral program.

Citizenship also has a significant effect at the doctoral level but operates differently than at the master's level. In the present study, Canadian citizenship is associated with a significant decrease in the length of time spent in the doctoral program. These data are in direct contradiction to the information presented by Yeates (1991), who observed that foreign students completed degrees more quickly than domestic students. No statistical analyses were performed by Yeates, however, and closer examination reveals that the largest differences in completion time between foreign and Canadian students occurred in engineering and applied science disciplines. These disciplines are not represented in the present study. Foreign students may prolong their tenure at the doctoral level in order to remain in the country longer, hoping to obtain landed-immigrant status. Perhaps the financial advantages of remaining in Canada with attendant employment flexibility and opportunity decrease the attractiveness of returning to the home country. Furthermore, at the conclusion of the doctoral years, the student is likely very comfortable and established in his or her environment and perhaps does not look forward to resettlement. Bowen and Rudenstine (1992) note that "increasing numbers of non-U.S. residents have chosen to stay on (at least temporarily) after graduation to continue their studies or research" (p. 32).

Being in a natural science discipline significantly decreases length of time to degree completion at the doctoral level. This variable accounts for a substantial proportion of the variance in length of time to completion and is the single most important contributor to speed of doctoral degree completion. This result supports the findings of many other scholars that program/discipline characteristics influence doctoral degree progress (Baird, 1990; Bowen \& Rudenstine, 1992; Duggan, 1989; Fletcher \& Stren, 1992; Girves \& Wemmerus, 1988; Yeates, 1991). Such differences in length of time to degree completion as a function of discipline have been observed consistently across cohorts and institutions (Bowen \& Rudenstine, 1992) and thus are considered to reflect intrinsic differences in the nature of graduate education in these disciplines.

Two of the financial variables, the average amount of funding received from all sources and the average amount of funding received from GAs, were significant predictors of length of time to degree completion at the doctoral 
level. Many authors have noted the importance of financial variables at the graduate level (Dolph, 1983; Teague-Rice, 1981; Tuckman et al., 1990). The findings of these investigators indicate that the less a student is forced to rely on personal finances, the better. The greater the amount of academically-linked financial support, the shorter the time required to complete the degree (Abedi \& Benkin, 1987; Bowen \& Rudenstine, 1992; Fletcher \& Stren, 1992; Tuckman et al., 1990).

The second of these variables, average amount of funding received from GAs, requires a more complex explanation. Abedi and Benkin (1987) found that doctoral students receiving grants and fellowships took longer to complete their degrees than did those receiving teaching or research assistantships. They speculated that this may be because these sources of funding force the student to spend an increased amount of time pursuing non-degree-related activities rather than increasing the amount of time devoted to full-time work towards the doctorate. In contrast, Tuckman et al. (1990) found that receipt of teaching and research assistantships significantly increased the length of time required to complete doctoral degrees while receipt of fellowship support decreased the length of time to doctoral degree completion. Bowen and Rudenstine (1992) similarly report that although teaching assistantships encourage participation in the graduate study enterprise, reliance on them significantly lengthens time taken to complete the doctorate, a phenomenon which they believe is currently increasing. Tuckman and his colleagues speculate that receiving support from teaching and research assistantships is often contingent upon performing duties that detract from degree-related pursuits. They reason that if such duties were related to the student's degree, doctoral degree completion would be facilitated rather than hindered.

For students in the present sample, GAs typically involve activities that facilitate doctoral degree completion rather than detract from it. Receipt of GA funds involves performance of duties which neither require the student to forego activities related to completing the degree (as may be the case with RAs and TAs, according to Tuckman et al., 1990), nor provide the student with an incentive to replace non-degree-related work with leisure activities rather than study time (as may be the case with grants and fellowships, according to Abedi and Benkin (1987)). Award of a GA allows students to receive payment for duties which do not detract from their degree progress, while at the same time their duties are regulated sufficiently (by the necessity of demonstrating progress as well as periodic evaluations by their supervisors), so that the incentive to replace work with leisure is not realizable. 
Neither the gender nor the age variable was a significant predictor of length of time to the doctorate. This fails to confirm the finding of Tuckman et al. (1990) that age of the student at time of entry into graduate school is the single most significant factor in increasing length of time to degree completion. The sample employed in the present study was representative of the population in terms of student age; therefore. it appears that age is not a significant factor in degree progress at this university.

Neither incoming grades nor graduate grades were significant in the regression analysis for doctoral degree progress. This replicates the finding of Girves and Wemmerus (1988) that grades are associated with degree progress at the master's but not at the doctoral level. This may be a consequence of the attenuated role of grades in evaluation at the doctoral level as well as the selection of higher-ability students for doctoral work.

Neither marital status nor leaves of absence were significant predictors of length of time to degree completion at the doctoral level, although this may reflect the sample size deficiency noted above.

\section{Summary and Implications}

The results from the separate regression solutions for length of time to degree completion at the master's and doctoral levels reveal that slightly different factor matrices affect length of time to degree completion. Registration status, discipline area, citizenship, and funding are significant predictors of length of time to degree completion at both levels, but the direction of the effect for area of study and citizenship is not consistent across levels. Other significant influences on time to completion are only relevant for master's students (graduate GPA, the thesis requirement, LOA).

Although the findings reported here hint at possible mechanisms for expediting degree progress, the situation is complex and further research is required before proceeding to implement radical changes. For example, conducting a thesis research project seems to militate against timely master's degree completion. If academic administrators are eager to diminish length of time to completion at the master's level, instituting a coursework-only option in disciplines not currently offering such an option might be considered. However, it may be that successful completion of a thesis facilitates more expeditious and/or qualitatively superior dissertation research. A study should be undertaken to determine if this is indeed the case. Potential disadvantages faced by doctoral students who have not fulfilled a thesis requirement might be offset by increasing the amount of faculty supervision provided. 
Similarly, although pursuing a degree on a part-time basis increases time to completion, restricting graduate study to a full-time model not only differentially limits accessibility but is inappropriate given the minimal level of support funding available for most students. Furthermore, given that part-time students typically receive no financial aid, they are not consuming monetary resources that could be directed to incoming students; and, therefore, part-time study may represent a cost-effective option for graduate training in some disciplines.

Clearly, the amount of financial support provided to graduate students affects time to completion. In this period of fiscal restraint, it is unlikely that current levels of support will be appreciably augmented, although this would operate to shorten the time taken to complete program requirements. Cooperative programs and/or paid internships or practica at the graduate level might alleviate the financial pressure on the student while at the same time freeing up some university resources which could then be made available to meet the escalating student demand for graduate study. Alternately, or in addition, the Yale model for funding senior students might be considered (Blum, 1990).

Among the intriguing findings of this research is the discovery that, at the master's level, those in humanities disciplines are faster completers than their counterparts in the natural sciences, while at the doctoral level, the reverse is true. With respect to the latter, Girves and Wemmerus (1988) have suggested that faculty in "hard" areas work within well-defined paradigms in which the content and methods that underlie research are well understood by those familiar with the paradigm. In "soft" areas, however, where research paradigms are less developed (and/or more variable), more time is required to describe and justify research, to delimit methodological approaches, and to establish criteria for evaluating such approaches (Biglan, 1973a, 1973b). Unfortunately, this very plausible construction does not explain the faster performance of humanities students at the master's level. One possible interpretation is that the discontinuity between undergraduate and master's level training in natural science disciplines is significantly greater than that in humanities disciplines. Conversely, at the doctoral level, the disjunction between the master's and doctoral level may be greater for humanities subjects than for natural science disciplines. These two propositions would account for the pattern of results obtained in the present study but must be tested in further research.

Decreasing the length of time required to complete the doctorate is viewed by some as the most critical problem facing graduate education at the present time (Tuckman et al., 1990). Increased TTD has many negative consequences, including lengthening the amount of time required for the supply of new doctor- 
ates to respond to shifts in market demand, discouraging students from pursuing training at the doctoral level or encouraging enrolled students to withdraw before completing their degrees, and decreasing the productivity of new doctorates by reducing the number of years spent working by degree-holders. Tuckman et al. note, however, that the data currently available to permit policy-makers to choose the best means of reversing increased time to the doctorate or to evaluate the consequences of any proposed solutions are as of yet still inadequate for such decision-making. Nevertheless, in the absence of definitive research, the Canadian Association of Graduate Schools (1987) has approved a document containing a number of recommendations designed to facilitate or expedite a student's progress through graduate program requirements. More recently, Yeates (1991) has similarly generated a set of recommendations geared to improve graduation rates and time to completion. The present study contributes additional information to this growing body of literature on master's and doctoral degree progress and provides some direction for future research considerations.

\section{References}

Abedi, J., \& Benkin, E. (1987). The effects of students' academic, financial, and demographic variables on time to the doctorate. Research in Higher Education, 27, 3-14.

Baird, L.L. (1990). Disciplines and doctorates: The relationships between program characteristics and the duration of doctoral study. Research in Higher Education, 31, 369-385.

Berelson, B. (1960). Graduate education in the United States. New York: McGraw-Hill.

Berg, H.M., \& Ferber, M.A. (1983). Men and women graduate students: Who succeeds and why? Journal of Higher Education, 54, 629-648.

Biglan, A. (1973a). The characteristics of subject matter in different academic areas. Journal of Applied Psychology, 57, 195-203.

Biglan, A. (1973b). Relationships between subject matter characteristics and the structure and output of university departments. Journal of Applied Psychology, 57, 204-213.

Blum, D.E. (1990, August 8). Yale plan to shorten duration of doctoral studies angers faculty members and graduate students. Chronicles of Higher Education, pp. 9, 12.

Bowen, W.G., \& Rudenstine, N.L. (1992). In pursuit of the Ph.D. Princeton, N.J.: Princeton University Press.

Canadian Association of Graduate Schools. (1987). On the time taken to complete graduate research degrees. Ottawa, Ontario, Canada: Author.

Carmichael, O.C. (1961). Graduate education: A critique and a program. New York: Harper \& Brothers. 
Cude, W. (1991). The need for improved doctoral program statistics. Canadian Journal of Higher Education, 21, 1-6.

Dolph, R.F. (1983). Factors relating to success or failure in obtaining the doctorate. Unpublished doctoral dissertation, Georgia State University.

Draper, N.R., \& Smith, H. (1981). Applied regression analysis (2nd ed.). New York: John Wiley \& Sons.

Duggan, J J. (1989). Time to the doctoral degree and success rates: The Berkeley experience. Unpublished data, University of California at Berkeley.

Evangelauf, J. (1989, March 15). Lengthening of time to earn a doctorate causes concern. Chronicle of Higher Education, 13-14.

Filteau, C. (Ed.). (1992). Graduate graduation rates and time-to-completion: Colloquium proceedings. Toronto, Ontario, Canada: Ontario Council on Graduate Studies.

Fletcher, J., \& Stren, R. (1992). Discussion of the factors influencing time-to-completion in graduate programmes: Student views. In C. Filteau (Ed.), Graduate graduation rates and time-to-completion: Colloquium proceedings. Toronto, Ontario, Canada: Ontario Council on Graduate Studies.

Girves, J.E., \& Wemmerus, V. (1988). Developing models of graduate student degree progress. Journal of Higher Education, 59, 163-189.

Harmon, L. (1978). A century of doctorates: Data analysis of growth and change. Report for the National Research Council. Washington, D.C.: National Academy Press.

Hosmer, D.W., Jr., \& Lemeshow, S. (1989). Applied logistic regression. New York: John Wiley \& Sons.

MacMillan, B. (1989). The flow-through hypothesis: A review of the data. In C. Filteau (Ed.), Proceedings of a conference of women in graduate studies in Ontario. Toronto, Ontario, Canada: Ontario Council on Graduate Studies.

Marr, W., \& McPherson, B. (1992). Graduation rates and time-to-completion in master's-only programmes. In C. Filteau (Ed.), Graduate graduation rates and time-to-completion: Colloquium proceedings. Toronto, Ontario, Canada: Ontario Council on Graduate Studies.

National Research Council. (1989). Summary Report 1987: Doctoral recipients from United States universities. Washington, D.C.: Author.

Ott, M.D., Markewich, T.S., \& Ochsner, N.L. (1984). Logit analysis of graduate student retention. Research in Higher Education, 21, 439-460.

Pyke, S.W., \& Sheridan, P.M. (1993). Logistic regression analysis of graduate student retention. Canadian Journal of Higher Education, 23, 44-64.

Sheinin, R. (1989). Review of the implementations of the recommendations of the Report on the "Status of Women in Ontario Universities." In C. Filteau (Ed.), Proceedings of a conference of women in graduate studies in Ontario. Toronto, Ontario, Canada: Ontario Council on Graduate Studies.

Sheridan, P.M. (1992). Factors influencing graduation rates and time-to-completion in master's programmes at York University. In C. Filteau (Ed.), Graduate graduation rates and time-to-completion: Colloquium proceedings. Toronto, Ontario, Canada: Ontario Council on Graduate Studies. 
Sheridan, P.M. (1990). Effects of demographic, academic and financial variables on graduate-student persistence, withdrawal and degree progress at York University. Unpublished master's thesis, York University, North York, Ontario, Canada.

SPSS. (1988). SPSS-X user's guide (3rd ed.). Chicago: Author.

Tabachnick, B.G., \& Fidell, L.S. (1983). Using multivariate statistics. Cambridge, M.A.: Harper \& Row.

Teague-Rice, L. (1981). A profile of the female doctoral student who persisted to the completion of the doctoral degree. Unpublished doctoral dissertation, Auburn University.

Tuckman, H.P., Coyle, S., \& Bae, Y. (1989). The lengthening of time to completion of the doctorate degree. Research in Higher Education, 30, 503-516.

Tuckman, H.P., Coyle, S., \& Bae, Y. (1990). On time to the doctorate. Washington, DC: National Academy Press.

Yeates, M. (1991). Doctoral graduation rates in Ontario universities. Toronto, Ontario, Canada: Council of Ontario Universities/Ontario Council on Graduate Studies. 